\title{
Intra- and interspecific behaviours in bank vole and striped-field mouse under enclosure conditions
}

\author{
Anna KOZAKIEWICZ and Paweł BONIECKI
}

\begin{abstract}
Kozakiewicz A. and Boniecki P. 1994. Intra- and interspecific behaviours in bank vole and striped-field mouse under enclosure conditions. Acta theriol. 39: 29-36.

Direct observations of the behaviour of bank voles Clethrionomys glareolus (Schreber, 1780) and striped-field mice Apodemus agrarius (Pallas, 1771) were carried out in semi-natural conditions (enclosure). Intra- and interspecific behaviours in both voles and mice were similar. A quick escape of animals was observed as a result of the majority of meetings (ca 70\%); fights among individuals were not frequent (usually about $10 \%$ of meetings). It seems that interactions among the two studied species have agonistic character, but none of them shows a visible domination over another. If competitive interactions among bank voles and striped-field mice take place, they have a character of exploitation; direct aggressive contacts are not the most important in competition.

Warsaw University, Institute of Zoology, Department of Ecology, Krakowskie Przedmieście 26/28, 00-927 Warsaw, Poland (AK), Institute of Ecology, Polish Academy of Sciences, Dziekanów Leśny (near Warsaw), 05-092 Łomianki, Poland (PB)

Key words: Clethrionomys glareolus, Apodemus agrarius, intra- and interspecific behaviours, competition
\end{abstract}

\section{Introduction}

The bank vole Clethrionomys glareolus (Schreber, 1780) and the striped-field mouse Apodemus agrarius (Pallas, 1771) are both non-specialist small rodent species. They differ only slightly from each other with regard to habitat preferences. Bank voles are typical forest inhabitants while striped-field mice can be found in meadows, crop fields and backyards as well as in wet bushy habitats and forest edges (e.g. Pucek 1981). However, there are some habitat types suitable for both of them, such as woodland or woodshrubs. Thus, temporal or even permanent co-occurence of the species can often be observed in woodland and bushy habitats. For example, in Poland they co-occur in many regions of the country: in southern Poland - Upper Silesia region (e.g. Chełkowska et al. 1985), in central Poland Warsaw region (e.g. Andrzejewski et al. 1978, Gliwicz 1981), in northern Poland - Masurian Lakeland (e.g. Kozakiewicz 1985, 1987).

The space use patterns of both species are comparable; they can also exploit similar food resources, although it can differ distinctly in different habitats and seasons (see Holišová 1967, Hansson 1985). Therefore, competitive interactions 
between bank voles and striped-field mice might be expected in habitats which are permanently or temporarily inhabited by both species.

Two kinds of interspecific competition or, according to some authors (see e.g. Miller 1967, Keddy 1989), its two component elements can be distinguished: interference and exploitation. Although these two terms are used sometimes in different ways, as is pointed out by Miller (1967), usually the term "interference competition" refers to direct competitive interactions among individuals while the term "exploitation" refers to indirect competitive interactions.

It is generally accepted that, in small rodents, direct aggressive contacts among individuals can play an important role as an expression of competitive interactions (Morris 1969, Morris and Grant 1972). When members of different species aggressively interact with one another, the potential for interference competition is especially strong. As is pointed out by Wiens (1989), one expression of interspecific aggression is a simple dominance of one species over another.

Aggressive interactions between individuals of different rodent species have been observed mainly in laboratory conditions and only occasionally in the wild (Grant 1972). Therefore, studies on the character of direct interactions between individuals of different species seem to be of high importance for understanding the processes of interspecific competition. In Poland only the direct interactions between bank voles and yellow-necked mice have previously been studied in the wild (Andrzejewski and Olszewski 1963).

In this paper we analyse the character of direct behavioural interactions between the striped-field mice and bank voles in semi-natural conditions.

\section{Material and methods}

Forty six bank voles and 25 striped-field mice were trapped in the mosaic farm-and-woodland habitats surrounding the enclosure into which they were placed for observations. An outdoor rodent-proof, fenced enclosure $30 \times 40 \mathrm{~m}$ was covered inside with natural vegetation: Urtica dioica, Taraxacum officinale, Artemisia vulgaris, Glechoma hederacea predominated. One permanent observation point was established outside the enclosure. A feeding tray (wooden box $40 \times 40 \times 20 \mathrm{~cm}$, without a front wall) was situated inside the enclosure, $2.5 \mathrm{~m}$ apart from observation point. The feeding tray was the only place inside the enclosure where food (oats, apples) and water were provided (always ad libitum).

There were two four-day repetitions of the experiment, carried out in August 1989 (15th-18th) and in July 1990 (9th-12th). During the first year of the studies the weather was changeable, two rainy days were recorded during the observation time, temperature varied from $17^{\circ} \mathrm{C}$ to $21^{\circ} \mathrm{C}$. In the second year the weather during the observations was very hot and dry: day-time temperatures were as high as $25-30^{\circ} \mathrm{C}$ while at night about $20^{\circ} \mathrm{C}$.

In the first year 21 voles and 10 mice were observed, while in the second year -25 voles and 15 mice. Densities of both species inside the enclosure were several times higher compared to those in natural conditions, but the numerical proportions of the species were similar to those in the wild.

Direct observations of behaviour of animals in a feeding tray were carried out during four full days (96 hours) each year. In night-time an electric light was used inside the feeding tray. Each entry of each individual to the feeding tray and each exit of each individual were noted. The total number 
of visits of individuals to the feeding tray $\left(N_{t}\right)$ was calculated separately for each species and each year of the studies.

It was calculated (for each year and for each species separately) how many times on average one individual visited the feeding tray during the time of a whole day, according to the formula:

$$
N_{v}=\frac{N_{t}}{N_{i} \times N_{d}}
$$

where: $N_{t}$ is the total number of visits to the feeding tray, $N_{i}$ is the number of individuals of a given species in the enclosure, and $N_{d}$ is the number of observation days.

If two or more individuals were present in the feeding tray at the same time, various kinds of direct contacts between them were observed: [1] avoidance, including (A) retreating - individuals retreat soon after they meet each other (within less than $30 \mathrm{sec}$ of meeting in the feeding tray) without a fight, (B) escaping after fight - individuals fight with each other before they escape. In some cases (less than $1 \%$ of the total number of observations) animals did not escape after the fight. These observations were not included in this analysis; [2] tolerance - individuals feed peacefully in the feeding tray for longer than $30 \mathrm{sec}$.

The proportions of different types of contacts (listed above) were calculated for the total number of observed meetings of individuals of the two species in the feeding tray. Inter- and intraspecific contacts among individuals were analyzed separately. The $\chi^{2}$-test was used to evaluate the statistical significance of differences between empirically estimated proportions and theoretically assumed equal probabilities of tolerance and avoidance (random contacts among the studied individuals).

\section{Results}

The total number of visits to the feeding tray of voles was 5204 in the first year of the studies and 3198 in the second year, while for mice it was respectively 852 and 544. On average, an individual of both vole and mouse visited the feeding tray about two times more frequently in a first series of observations than in a second series. In both series the voles visited the feeding tray about three times more frequently than the mice (Table 1).

Considering the number of individuals and species present at the same time in the feeding tray, the following kinds of situations were observed: (1) only single vole individual present, (2) only single mouse individual present, (3) two or more voles present simultaneously, (4) two or more mice present simultaneously, (5) individuals of the two species present simultaneously. Overall, the above situations were observed as much as 4407 times during the first year of the studies, while in the second year it was only 2779 times.

Table 1. The average number of visits to the feeding tray $\left(N_{v}\right)$ for one bank vole $(C . g$.$) and one striped-field mouse$ (A. a.) during one day (24 hours) in the first (I) and second (II) year of observations.

\begin{tabular}{lcc}
\hline \multirow{2}{*}{$\begin{array}{l}\text { Year of } \\
\text { observations }\end{array}$} & \multicolumn{2}{c}{$N_{v}$} \\
\cline { 2 - 3 } & C.g. & A. $a$. \\
\hline I & 62 & 21 \\
II & 32 & 9 \\
\hline
\end{tabular}


For each year of the studies separately, the percentages of all these observed kinds of situations were calculated for the total number of observations. Single individuals were observed in the feeding tray most often (more than $60 \%$ of the total number of the observations in each year of the studies). Single voles were observed in the feeding tray in about $50 \%$ of the observations in each year, while single mice - in less than $20 \%$ of the observations. Simultaneous presence of the individuals of the two species in the feeding tray was observed very rarely (about $5 \%$ of the observations in each year; Fig. 1).

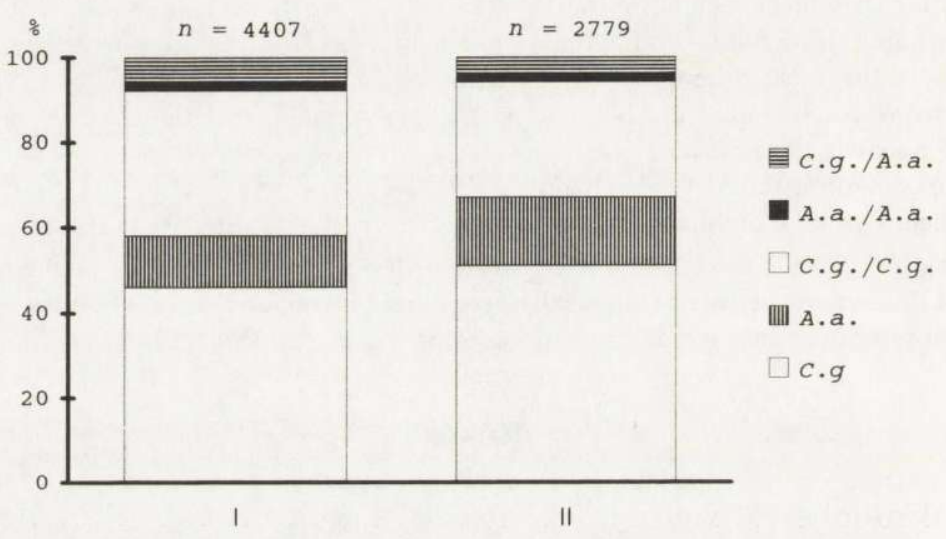

Fig. 1. The percentages of the different kinds of the situations observed in the feeding tray, distinguished basing on the number of species and individuals present at the same time, calculated for the total number of observations. C. g. - only single vole individual present, A. $a$. - only single mouse individual present, C.g./C.g. - two or more voles present simultaneously, A. a. /A. a. - two or more mice present simultaneously, C.g./A. $a$. - individuals of the two species present simultaneously, $n-$ number of observations, I - the first year of observations, II - the second year of observations.

$$
\text { C.g. A.a. C.g/A.a. }
$$

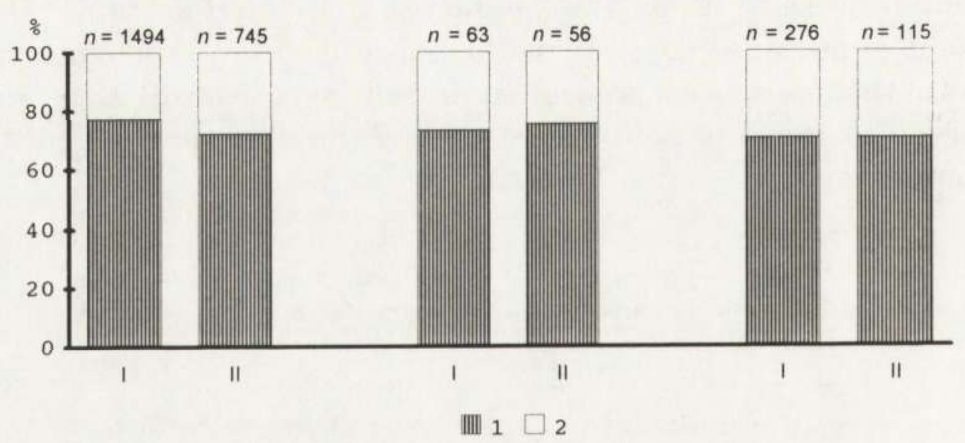

Fig. 2. The percentages of mutual avoidance and tolerant reactions of individuals in the feeding tray. C.g. - meetings of voles only, A.a. - meetings of mice only, C.g./A.a. - meetings of voles and mice, 1 - avoidance, 2 - tolerance, $n$ - number of meetings observed, I - first year of observations, II - second year of observations. 
Higher proportions of mutual avoidance than tolerance reactions were observed when two or more individuals of the same species met in the feeding tray, both in mice and in voles (proportions differ significantly from randomness for both series of observations: for voles $\chi^{2}=434.8$ for first year and 142.8 for the second year; for mice it is respectively 16.3 and 14.0. For both species $k=1$ and $p<0.001$ ) (Fig. 2).

A simultaneous presence in the feeding tray of individuals of the two species was observed 276 times in a first series of observations and 115 times in a second series of observations. Avoidance of species was more frequently observed than tolerance (proportions differ significantly from randomness, $\chi^{2}=43.8$ for a first year and 19.2 for a second year, $k=1, p<0.001$ ) (Fig. 2).

In general, a quick escape of animals was observed as a result of the majority (ca $70 \%$ ) of meetings (Fig. 2). In as many as more than $60 \%$ of observations of mutual avoidance of individuals, an individual that entered the feeding tray which was already occupied by other individual(s), was the only one that escaped. The escape of all individuals present in the feeding tray was noted in about $20 \%$ of observations (Fig. 3). In both years of the studies the frequencies of meetings that were followed by escape of individuals entering the feeding tray were higher than those followed by escape of individuals already present there (proportions differ significantly from randomness for both series of observations: for voles $\chi^{2}=230.8$ for first year and 147.4 for the second year; for mice it is respectively 8.6 and 11.5 ; for both species it is 52.9 and 17.7 respectively; $k=1$ and $p<0.001$ in all cases except for mice in the first year of the studies where $p<0.01$ ).

Direct fights between individuals, both inter- and intraspecific, were observed rarely. Among voles fights were noted in $11 \%$ of a total number of observations, while among mice it was a little less than $10 \%$. Interspecific fights were noted only in about $10 \%$ of observations in the first year of the studies, while in as much as in almost $30 \%$ in the second year (differences statistically significant, test for

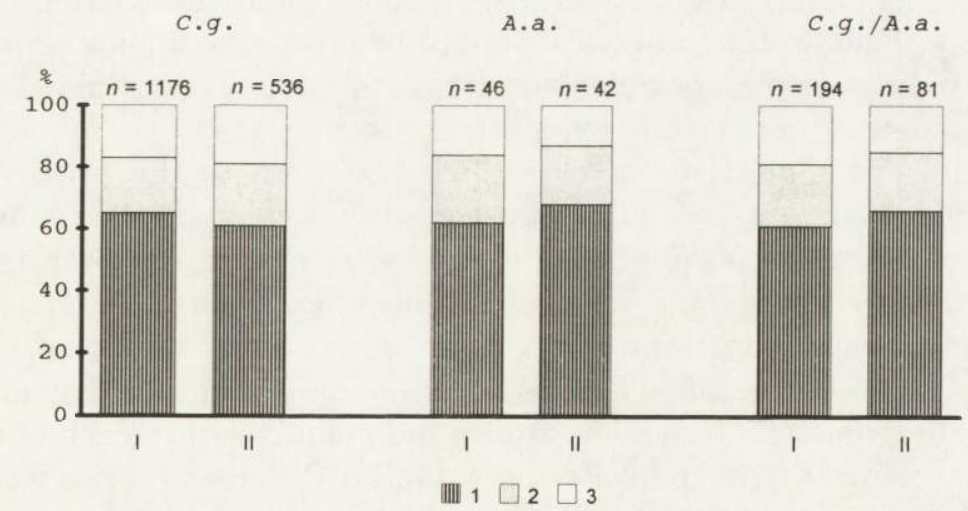

Fig. 3. The percentages of different kinds of reactions of mutual avoidance of individuals in the feeding tray. 1 - escape of individual entering the feeding tray only, 2 - escape of all individuals, 3 - escape of individual(s) already present in the feeding tray only. For more explanation see Fig. 2. 


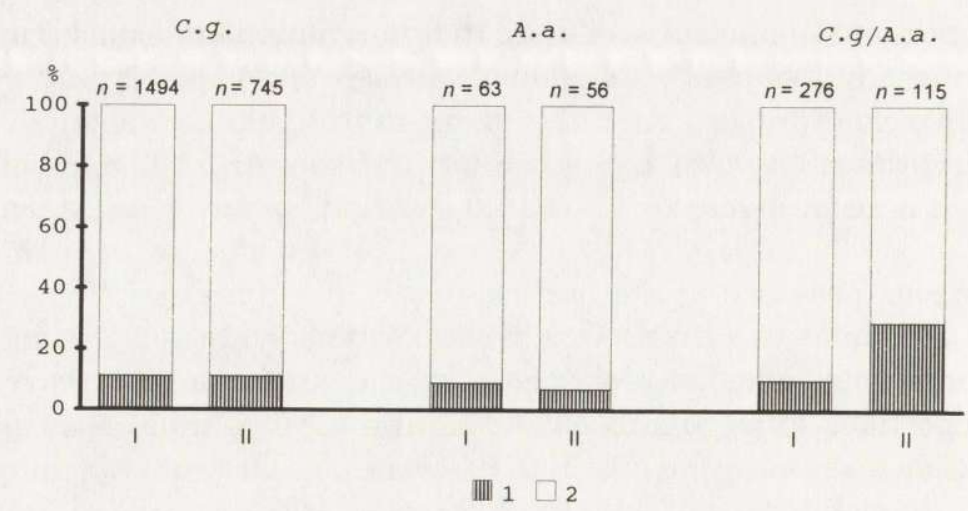

Fig. 4. The percentages of meetings followed by fights among individuals in a total number of meetings observed. 1 - meetings followed by fights, 2 - meetings without fights. For more explanation see Fig. 2 .

examining the statistical differences between proportions: $\mathrm{d}=4.4, \mathrm{k}=\infty, p<0.001$ (Fig. 4). Neither mice nor voles were more aggressive in interspecific fights: mice actively attacked voles in $63 \%$ and $67 \%$ of the interspecific fights observed in the first and second years of studies respectively, but these proportions are not statistically different from randomness $\left(\chi^{2}\right.$-test, $\chi^{2}=1.8$ and 3.7 , respectively).

\section{Discussion}

Both voles and mice visited the feeding tray about two times more frequently in the first than in the second year of observations. This was possibly due to the differences in the activity of rodents in these two years, caused probably by different weather conditions or the slightly different time of observations.

On the other hand, in both years, the voles visited the feeding tray several times more frequently than mice. This might be due to the higher activity of voles or to their need to feed more frequently than mice. However, it may be the result of the reluctance of mice to meet voles in the feeding tray.

The behavioural reactions of both mice and voles to the presence of other individuals of their own as well as of other species were similar. A quick escape of animals entering the feeding tray (directly after meeting or after a short fight) took place as a result of the majority of meetings (Figs 2, 3) indicating, that interactions are mostly intolerant in nature. These results show that non-tolerant interactions among the studied species can take place, and that they are as strong as similar antagonistic interactions among individuals within each of the species.

In our experiment fights between individuals of different species were observed infrequently (Fig. 4). It can be suggested that the higher percentage of fights between individuals of different species observed in the second year of the studies, was caused by the higher density of animals in the enclosure this year. It is widely 
accepted that in small mammals the increase in population density can result in the increase of aggressiveness of individuals. In our experiment, however, it applied only to interspecific fights; the intensity of fights between individuals of the same species remained unchanged in the second year of the studies.

In the literature it is suggested that individuals of the genus Apodemus are dominant over Clethrionomys (see Gurnell 1985). Our data do not confirm these statements. Direct fights between individuals were observed very rarely. If so, neither mice nor voles were more aggressive. In the majority of observations of mutual avoidance of individuals, animal entering the already occupied feeding tray was the one that escaped. All these results suggest that despite voles and mice seem to be malevolent to each other, none of the species dominates over another. This may be due to the similar size of the individuals of both species. The difference in the size of the individuals in competing species are often considered to be an important factor causing the dominance of one species (the larger one) over another (the smaller) (e.g. Grant 1972, Schoener 1983). It should be noted, however, that other studies indicate that mutual interactions among bank voles and striped-field mice can be strongly affected by the quality of the habitat which they occupy (Kozakiewicz et al. 1987). In some cases it has been shown that there is restrictive influence of bank voles on the density and/or spatial distribution of striped-field mice (Gliwicz 1981, Suska 1985, Kozakiewicz 1987).

In conclusion, it seems that individual bank voles and striped-field mice show a tendency to non-tolerant mutual interactions, not stronger, however, than those in relation to individuals of their own species. None of the studied species shows a strong tendency to dominate over the other. Thus the manner and effects of interactions among bank voles and striped-field mice can be classified as type III A according to the classification proposed by Gurnell (1985): “... neither species dominates over the other ... processes similar for both species: changes of diet, differential activity in time and space occur in both species ...". It seems that, if competitive interactions among bank voles and striped-field mice take place, they have a character of exploitation rather than of interference - direct aggressive interactions among individuals are rare and not substantial in creating the dominance. However, the manner and effects of interactions among individuals may be affected strongly by environmental factors (habitat quality and richness, habitat spatial structure), creating better living conditions for one species or another. The present experiment was carried out in semi-natural conditions and further observations are needed to assess the nature of the interactions under different environmental conditions.

\section{References}

Andrzejewski R., Babińska-Werka J., Gliwicz J. and Goszczyński J. 1978. Synurbization processes in population of Apodemus agrarius. I. Characteristics in populations in an urbanization gradient. Acta theriol. 23: 341-358. 
Andrzejewski R. and Olszewski J. 1963. Social behaviour and interspecific relations of Apodemus flavicollis (Melchior 1834) and Clethrionomys glareolus (Schreber, 1780). Acta theriol. 7: 155-168.

Chełkowska H., Walkowa W. and Adamczyk K. 1985. Spatial relationships in sympatric populations of the rodents Clethrionomys glareolus, Microtus agrestis and Apodemus agrarius. Acta theriol. 30 : $51-78$.

Gliwicz J. 1981. Competitive interactions within a forest rodent community in central Poland. Oikos 37: 353-362.

Grant P. R. 1972. Interspecific competition among rodents. Ann. rev. Ecol. Syst. 3: 79-104.

Gurnell J. 1985. Woodland rodent communities. [In: The ecology of woodland rodents: bank voles and wood mice. J. R. Flowerdew, J. Gurnell and J. H. W. Gipps, eds]. Symp. Zool. Soc. Lond. No. 55, Clarendon Press, Oxford: 377-411.

Hansson L. 1985. The food of bank voles, wood mice and yellow-necked mice. [In: The ecology of woodland rodents: bank voles and wood mice. J. R. Flowerdew, J. Gurnell and J. H. W. Gipps, eds]. Symp. Zool. Lond. No. 55, Clarendon Press, Oxford: 141-168.

Holišová V. 1967. The food of Apodemus agrarius. Zool. Listy 16: 1-14.

Keddy P. A. 1989. Competition. Population and community biology series. Chapman and Hall. London, New York: 1-202.

Kozakiewicz A. 1985. Lakeside communities of small mammals. Acta theriol. 30: 171-191.

Kozakiewicz A. 1987. Spatial distribution and interspecific interactions in small rodent community of lake coastal zone. Acta theriol. 32: 433-447.

Kozakiewicz M., Kozakiewicz A. and Banach A. 1987. Effect of environmental conditions on character of spatial interactions among three small rodent species. Bull. Acad. Pol. Sci. Cl. II. 35: 182-188.

Miller R. S. 1967. Pattern and processes in competition. Adv. Ecol. Res. 4: 1-74.

Morris R. D. 1969. Competitive exclusion between Microtus and Clethrionomys in the aspen parkland of Saskatchewan. J. Mammal. 50: 291-301.

Morris R. D. and Grant P. R. 1972. Experimental studies of competitive interaction in a two-species system. IV. Microtus and Clethrionomys species in a single enclosure. J. anim. Ecol. 41: 275-290.

Pucek Z., ed. 1981. Keys for identifying mammals of Poland. PWN. Warszawa: 1-367.

Schoener T. W. 1983. Field experiments on interspecific competition. Am. Nat. 122: 240-285.

Suska M. 1985. [Competitive interactions in small rodents community inhabiting the lakeside zone.] M. Sc. thesis, Department of Biology, Warsaw University: 1-34. [In Polish]

Wiens J. A. 1989. The ecology of bird communities. vol. 2. Processes and variations. Cambridge Univ. Press. Cambridge, N.Y., Port Chester, Melbourne, Sydney: 1-316.

Received 30 November 1992, revised 5 Novemebr 1993, accepted 20 December 1993. 